\title{
Role of platelet activating factor in pathogenesis of acute pancreatitis in rats
}

\author{
S J Konturek, A Dembinski, P J Konturek, Z Warzecha, J Jaworek, P Gustaw, R Tomaszewska, \\ J Stachura
}

\begin{abstract}
The importance of platelet activating factor in acute pancreatitis was examined by determining the tissue content of endogenous platelet activating factor and the protective effects of TCV-309, a highly selective platelet activating factor blocker, against caerulein induced pancreatitis in rats. Infusion of caerulein $(10 \mu \mathrm{g} /$ $\mathrm{kg} / \mathrm{h}$ ) for five hours resulted in about $70 \%$ increase in pancreatic weight, $22 \%$ rise in protein content, $50 \%$ reduction in tissue blood flow, nine fold increase in tissue level of platelet activating factor and $165 \%$ rise in plasma amylase as well as histological evidence of acute pancreatitis. Such infusion of caerulein in chronic pancreatic fistula rats caused a marked increase in protein output from basal secretion of $10 \mathrm{mg} / 30$ minutes to 40 $\mathrm{mg} / 30$ minutes in the first hour of infusion followed by a decline in protein output to 15-20 $\mathrm{mg} / 30$ minutes in the following hours of the experiment. Exogenous platelet activating factor $(50 \mu \mathrm{g} / \mathrm{kg})$ injected ip produced similar alterations in weight, protein content, blood flow, and histology of the pancreas but the increment in serum amylase was significantly smaller and pancreatic secretion was reduced below the basal level. TCV-309 $(50 \mu \mathrm{g} / \mathrm{kg})$ given ip before caerulein or platelet activating factor administration significantly reduced the biochemical and morphological alterations caused by caerulein and abolished those induced by exogenous platelet activating factor. These results indicate that platelet activating factor plays an important role in the pathogenesis of acute pancreatitis probably by reducing the blood flow and increasing vascular permeability in the pancreas.

(Gut 1992; 33: 1268-1274)
\end{abstract}

Acute pancreatitis is a severe disease with signifcant morbidity and mortality for which no specific treatment exists. Several experimental models of acute pancreatitis have been produced by various methods but one of the most frequently used involves an excessive stimulation of pancreatic secretion by the administration of supramaximal dose of caerulein'2 or cholecystokinin octapeptide. ${ }^{3}$

Caerulein induced pancreatitis represents a reproducible model suitable to study the effects of potentially ameliorating agents but the mechanism of the pancreatic damage has not been fully explained. The discharge of secretory proteins into the interstitial space because of excessive pancreatic stimulation and resulting oedema with accumulation of leucocytes are the major changes described in the caerulein induced pancreatitis. $^{3}$
It has been reported ${ }^{4}$ that pancreatic acinar cells, stimulated by caerulein or cholecystokinin, release substantial amounts of platelet activating factor. Platelet activating factor is a low molecular weight phospholipid exhibiting potent biological effects including the platelet and neutrophil aggregation, systemic hypotension, pulmonary hypertension, and capillary leakage ${ }^{\text {* }}$ leading to haemorrhagic damage in the gastrointestinal tract.?

Emanuelli et $a l^{8}$ reported that an injection of platelet activating factor into the superior pancreaticoduodenal artery induced the changes in the rabbit pancreas characteristic of acute pancreatitis. These findings suggest that platelet activating factor may be involved in the progression of acute pancreatitis caused by infusion of caerulein but there is no experimental evidence so far to support this notion. Development of specific platelet activating factor blockers ${ }^{y}$ such as TCV $-309^{10}$ has enabled us to examine the role of platelet activating factor in the pathogenesis of caerulein induced acute pancreatitis.

\section{Methods}

\section{MATERIALS}

Platelet activating factor (1-0-alkyl-2-0-acetylsn-glycero-3-phospho-choline) was purchased from Bachem Feinchemikalien AG (Bubendorf, Switzerland). The stock solution (in ethanol) was stored at $-40^{\circ} \mathrm{C}$. Working solution was made fresh daily. TCV-309 is 3-Bromo-5-[Nphenyl $\vee N[2-(1,2,3,4-t e t r a h y d r o-2-i s o q u i n o l y l-$ carbonyloxy)ethyl]carbamoyl]-1-propylpyridinium kindly provided as a gift by Dr Y Oka from Takeda Industries, Osaka, Japan. The aqueous solution was made fresh daily and used in the rats at a dose 10 times higher $(50 \mu \mathrm{g} / \mathrm{kg})$ than that shown in separate experiments on these animals to reduce by $50 \%$ the platelet activating factor induced hypotension ( ID $_{50}=5 \mu \mathrm{g} / \mathrm{kg} \mathrm{ip}$ ). The concentration of TCV-309 reducing by $50 \%$ platelet activating factor induced aggregation of human or rabbit platelets was found to be $10^{7}$ $\mathrm{M}^{10}$ and this concentration was used in the in vitro studies on the dispersed pancreatic acini.

Male Wistar rats weighing 250-300 g, were used in this study to examine the pancreatic secretion and pancreatic blood flow during infusion of caerulein and to examine the involvement of platelet activating factor in the pathogenesis of acute pancreatitis.

EXAMINATION OF PANCREATIC SECRETION IN VIVO Pancreatic secretion was examined in rats with chronic pancreatic fistula prepared as described previously." Briefly, one polyethylene cannula 
was inserted into the common bile pancreatic duct to serve as the pancreatic fistula. This cannula was connected to another polyethylene cannula placed in the duodenum to permit the circulation of the pancreatic secretion into the duodenum. Both cannulae were brought to the exterior and protected by a stainless steel thimble allowing for the free movement of rats in their usual cages. During experiment they were placed in modified Bollman type cages to maintain the minimum restraint necessary. The metal thimble was removed, the cannulae were disconnected, the pancreatic cannula was used to collect the pure pancreatic juice, and the duodenal cannula was used for the reinfusion of the juice (diluted by saline 1:2) into the duodenum. The secretory studies usually started after six to eight days of recovery from the surgery usually after 12 hours of food but not water deprivation. The pancreatic secretion was collected from the pancreatic fistula in small preweighed vials in $\mathbf{3 0}$ minute aliquots to measure the volume flow and protein outputs as described previously." A duodenal cannula was used for the reinfusion of the collected pancreatic secretion (diluted by saline 1:2).

Several series of rats, each comprising six to eight animals, with chronic pancreatic fistula were used in secretory studies with the five hour return of pancreatic secretion to the duodenum. The following series were used; (i) sc infusion of saline (rate $1 \mathrm{ml} / \mathrm{h}$ ) throughout the seven hour experiment; (ii) sc infusion of caerulein $(10 \mu \mathrm{g} /$ $\mathrm{kg} / \mathrm{h}$, rate $1 \mathrm{ml} / \mathrm{h}$ ) throughout five hour period; (iii) ip injection of TCV $-309(50 \mu \mathrm{g} / \mathrm{kg})$ in $1 \mathrm{ml}$ of saline) followed 90 minutes later by sc infusion of caerulein for the rest of experiment; (iv) ip administration of platelet activating factor (50 $\mu \mathrm{g} / \mathrm{kg}$ ) followed by sc infusion of saline for the duration of experiment; (v) ip injection of TCV309 followed 30 minutes later by ip platelet activating factor and then by sc infusion of saline for the duration of experiment.

Rats used for studies with production of pancreatitis were allowed free access to water but no food for 18 hours before the beginning of experiment. Pancreatitis was induced by caerulein that was diluted in saline and infused sc for five hours in conscious animals at a dose of 10 $\mu \mathrm{g} / \mathrm{kg} / \mathrm{h}$ and at a rate of $1 \mathrm{ml} / \mathrm{h}$. The infusion usually started at 800 am at which time water was removed. The needle was inserted under the dorsal skin and attached to a tygon tubing (Irvington brand, size 24, 3 M Company, Minneapolis, Minnesota, USA), which was connected to a $10 \mathrm{ml}$ plastic syringe. During the infusion, the animals were kept in semirestraining Bollman type cages as used also in secretory studies. About five hours after the beginning of caerulein infusion, the animals were anaesthetised with ether, the abdominal cavity was opened, and the pancreas exposed for measurement of the blood flow by the laser Doppler flowmeter using Laserflo, model BPM 403A, Blood Perfusion Monitor (Vasamedics Inc, St Paul, MN, USA). Blood flow was measured in three different portions of the pancreas and the area of laser emission of the probe was $1 \mathrm{~mm}^{2}$. As the depth of measurement by the laser Doppler flowmeter is about $3-5 \mathrm{~mm}$, the technique used determined total pancreatic blood flow. In a separate series of experiments, the progression of the changes in pancreatic blood flow was determined in rats anaesthetised with ether at 60 minute intervals twice before and five times during a five hour infusion of caerulein $(10 \mu \mathrm{g} / \mathrm{kg} / \mathrm{h})$. In control tests, the blood flow was measured at 60 minute intervals during the seven hour infusion of saline.

The pancreatic blood flow was recorded in $\mathrm{ml} /$ $\mathrm{min} / 100 \mathrm{~g}$ tissue as displayed on the digital panel meter and presented either in absolute value or as per cent change from control value obtained in rats infused with saline.

Immediately after measurement of pancreatic blood flow, the vena cava was exposed and blood was drawn into a $2 \mathrm{ml}$ plastic syringe containing $0.2 \mathrm{ml}$ heparin (200 IU) (Polfa, Poland). Plasma amylase was determined by an enzymatic method using Bernfeld technique. ${ }^{12}$ The values were expressed as units/litre.

\section{HISTOLOGICAL EXAMINATION}

The pancreas was then quickly dissected out from its attachment to the stomach, the duodenum, and the spleen, rinsed with saline, blotted on paper and weighed. Some pieces of pancreas were excised from the body portion, fixed in $10 \%$ formalin and stained with haematoxylin and eosin. The slides were examined histologically without the knowledge of the treatment given. The histologic grading of oedema was made using a scale ranging from 0 to 3 ; $0=$ no oedema, $1=$ interlobular oedema, $2=$ interlobular oedema and moderate intralobular oedema, and $3=$ interlobular oedema and severe intralobular oedema. Leucocytic infiltration was graded from 0 (absent) to 3 for maximal alterations (diffuse infiltration in the entire pancreatic gland). Grading of vacualisation was based on the appropriate percentage of cell involved; $0=$ absent, $1=$ less than $25 \%, 2=25-50 \%$, and $3=$ more than $50 \%$.

\section{DETERMINATION OF PANCREATIC PROTEIN AND} PLATELET ACTIVATING FACTOR

A portion of the pancreatic tissue (about $200 \mathrm{mg}$ wet weight) was homogenised in $0.15 \mathrm{M} \mathrm{NaCl}$ solution using high frequency $(24000 \mathrm{rpm})$ Tissumizer (Ika Lab, Staufen, Germany). Protein content was determined by the method of Lowry $e t a l^{13}$ with bovine plasma albumin as a standard and expressed as milligrams of protein per total pancreatic tissue wet weight.

The content of platelet activating factor in pancreatic tissue was determined using bioassay technique with washed rabbit platelets as described previously. ${ }^{1+}$ About $100 \mathrm{mg}$ pancreatic tissue was excised and frozen at $-20^{\circ} \mathrm{C}$ until assay performed two to four days afterwards. About 24 hours before assay the sample was placed in $80 \%$ ethanol to extract platelet activating factor from the tissue. Biological activity of platelet activating factor was measured by platelet aggregation using a Chrono-log Corporation aggregometer. Platelets were stirred in 400 $\mu$ l buffer containing $2.6 \mathrm{mM} \mathrm{KCl}, 1 \mathrm{mM} \mathrm{MgCl}$, $137 \mathrm{mM} \mathrm{NaCl}, 12 \mathrm{mM} \mathrm{NaHCO}, 1.3 \mathrm{mM} \mathrm{CaCl}_{2}$, 


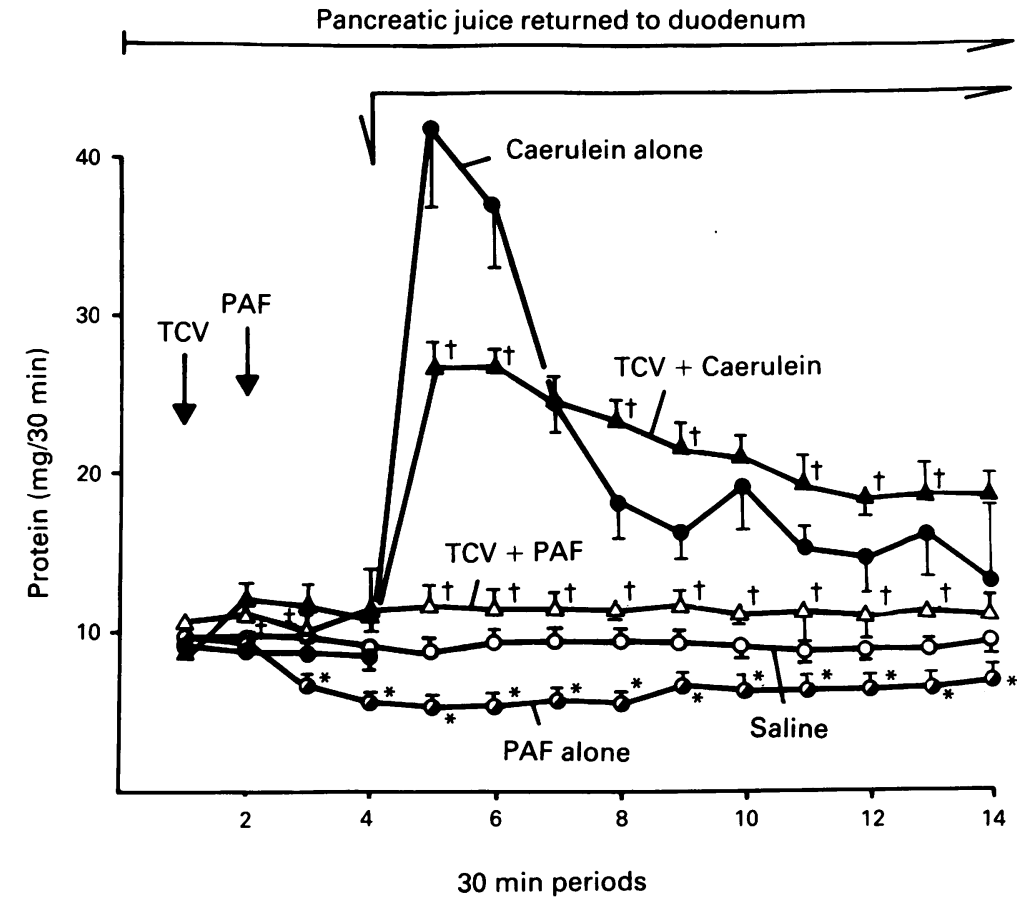

Figure 1: Pancreatic protein outputs from chronic pancreatic fistula under basal conditions with sc infusion of saline and after infusion of caerulein alone $(10 \mu \mathrm{g} / \mathrm{kg} / \mathrm{h} \mathrm{sc})$, platelet activating factor $(P A F)$ alone $(50 \mu \mathrm{g} / \mathrm{kg}$ ip) and TCV-309 $(50 \mu \mathrm{g} / \mathrm{kg}$ ip) followed by caerulein or platele activating factor. Means (SEM) of six to eight rats per group. Asterisk indicates significant $(p<0.05)$ decrease below the basal value. Cross indicates significant $(p<0.05)$ change as compared with caerulein or platelet activating factor alone.

$5.5 \mathrm{mM}$ glucose, 0.25 gelatine, $1 \mathrm{mM}$ creatine phosphate and $10 \mathrm{IU} / \mathrm{ml}$ creatine phosphokinase (pH 7·4). Standard curves were obtained using synthetic platelet activating factor (Bachem, Switzerland), which produced typical dose dependant platelet aggregation when added at $0 \cdot 5-50 \mathrm{pg} /$ tube.<smiles>[CH]C</smiles>

\section{EXAMINATION OF SECRETORY ACTIVITY OF \\ DISPERSED PANCREATIC ACINI}

Isolated pancreatic acini were prepared as described previously ${ }^{15}$ by collagenase digestion of the pancreas obtained from saline treated rats and those receiving infusion of caerulein alone, platelet activating factor alone, TCV-309+ caerulein or TCV+platelet activating factor. Animals in this series of experiments were killed

TABLE I Amylase release expressed as per cent of total amylase release from isolated pancreatic acini obtained from the rats infused with saline, caerulein, caerulein $+T C V-309$, platelet activating factor or platelet activating factor $+T C V-309$, in response to graded concentrations of caerulein

\begin{tabular}{|c|c|c|c|c|c|c|}
\hline & \multicolumn{5}{|c|}{$\begin{array}{l}\text { Amylase release }(\%) \\
\text { Caerulein concentration }(M)\end{array}$} & \multirow{2}{*}{$\begin{array}{l}\text { Volume of } \\
\text { pancreatic } \\
\text { acini }(m l)\end{array}$} \\
\hline & 0 & $10^{-12}$ & $10^{11}$ & $10^{-10}$ & $10^{-9}$ & \\
\hline $\begin{array}{l}\text { Saline (control) } \\
\text { Caerulein } \\
\text { Caerulein+TCV-309 } \\
\text { PAF } \\
\text { PAF+TCV-309 }\end{array}$ & $\begin{array}{l}4 \cdot 5(0 \cdot 4) \\
6 \cdot 3(0 \cdot 8) \\
5 \cdot 2(0 \cdot 7) \\
7 \cdot 8(0 \cdot 2) \\
7 \cdot 3(0 \cdot 5)\end{array}$ & $\begin{array}{l}12 \cdot 9(0 \cdot 0) \\
12 \cdot 2(1 \cdot 0) \\
13 \cdot 8(0 \cdot 8) \\
13 \cdot 1(0 \cdot 2) \\
12 \cdot 2(0 \cdot 2)\end{array}$ & $\begin{array}{l}17 \cdot 2(0 \cdot 2) \\
14 \cdot 0(0 \cdot 7)^{\star} \\
15 \cdot 2(0 \cdot 4)^{\star} \\
14 \cdot 3(0 \cdot 2)^{\star} \\
16 \cdot 4(0 \cdot 9)\end{array}$ & $\begin{array}{l}16 \cdot 5(0 \cdot 3) \\
16 \cdot 9(0 \cdot 7) \\
16 \cdot 9(0 \cdot 6) \\
15 \cdot 5(0 \cdot 7) \\
13 \cdot 0(0 \cdot 7)\end{array}$ & $\begin{array}{l}15 \cdot 2(0 \cdot 2) \\
14 \cdot 1(0 \cdot 1) \\
14 \cdot 9(0 \cdot 3) \\
14 \cdot 5(0 \cdot 2) \\
12 \cdot 1(1 \cdot 2)\end{array}$ & $\begin{array}{l}2.2(0.3) \\
0.8(0.1)^{\star} \\
1.5(0.3) \dagger \\
0.9(0.2)^{\star} \\
1.8(0.4) \dagger\end{array}$ \\
\hline
\end{tabular}

The volume of pancreatic acini per rat obtained in above experiments is given. Mean (SEM) of eight to 10 rats. ${ }^{\star}$ Indicates significant $(p<0 \cdot 05)$ decrease below the value obtained from acini of rats infused with saline. +Indicates significant increase above the value obtained from acini of rats with infusion of caerulein or injection of platelet activating factor.

$\mathrm{PAF}=$ platelet activating factor by cervical dislocation, the pancreas was removed and then digested by highly purified collagenase (CLSPA, $540 \mathrm{IU} / \mathrm{mg}$, Cooper Biomedical, Freehold, NJ, USA) according to the method of Amsterdam et al. ${ }^{16}$ The volume of dispersed acini from each pancreas was measured and then the acini were suspended in the incubation medium saturated with oxygen and maintained at $37^{\circ} \mathrm{C}$ in a shaking bath. Acinar suspensions were incubated in the presence of various concentrations of caerulein. After incubation, tubes were centrifuged at $1000 \mathrm{~g}$ and the supernatant separated from the pellet. Amylase content in the supernatant and dissolved pellet were determined as described by Bernfeld. ${ }^{12}$ Unstimulated amylase release $(\mathrm{C}=$ control) during the entire experimental period was also determined and presented as basal value.

EXPERIMENTAL PROTOCOL WITH PANCREATITIS

Control experiments were first performed in which rats received sc infusion of saline $(1 \mathrm{ml} / \mathrm{h})$ (control) for five hours or sc infusion of caerulein $(10 \mu \mathrm{g} / \mathrm{kg} / \mathrm{h})$ for five hours. After determination that sc infusion of caerulein resulted in induction of acute pancreatitis four separate groups of rats, each consisting of six to eight animals were given (i) sc infusion of caerulein alone; (ii) ip injection of platelet activating factor $(50 \mu \mathrm{g} / \mathrm{kg}$ ), (iii) TCV-309 ip $(50 \mu \mathrm{g} / \mathrm{kg})$ and then 30 minutes later sc infusion of caerulein for five hours, and (iv) TCV-309 ip ( $50 \mu \mathrm{g} / \mathrm{kg})$ and then 30 minutes later platelet activating factor $(50 \mu \mathrm{g} / \mathrm{kg} \mathrm{ip})$ and then 30 minutes later sc infusion of saline for five hours.

\section{STATISTICAL ANALYSIS}

Comparison of the difference between the mean values of the various groups of experiments was made by analysis of variance or the Wilcoxon's rank-sum test. A difference with a $p$ value of less than 0.05 was considered statistically significant. Results are expressed as means (SEM).

\section{Results}

PANCREATIC SECRETION IN VIVO AND IN VITRO In rats with chronic pancreatic fistula, the basal pancreatic protein secretion was well sustained at a level of about $10 \mathrm{mg} / 30$ minutes throughout the seven hour experiment (Fig 1). Subcutaneous infusion of caerulein $(10 \mu \mathrm{g} / \mathrm{kg} / \mathrm{h})$ for five hours resulted in almost immediate increase in protein secretion reaching the peak of about $40 \mathrm{mg} / 30$ minutes during the first hour. Then the secretory rate declined during the second and third hours to the level of about $15-20 \mathrm{mg} / 30$ minutes and remained at this level during the fourth and fifth hour of caerulein infusion.

Pretreatment with TCV-309 $(50 \mu \mathrm{g} / \mathrm{kg}$ ip $)$ did not affect basal secretion but reduced by about $40 \%$ the initial peak secretory response to caerulein and significantly $(p<0.05)$ enhanced the protein outputs in next hours of caerulein infusion.

Administration of platelet activating factor ( 50 


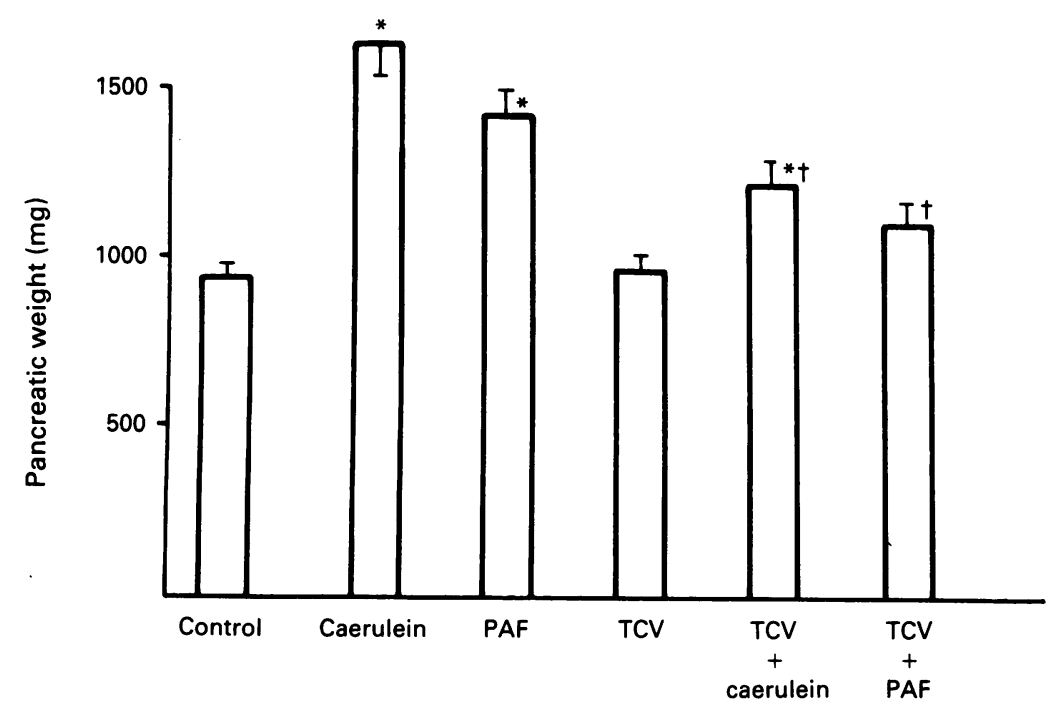

Figure 2: Weight of the pancreas of rats infused sc for five hours with saline (control),

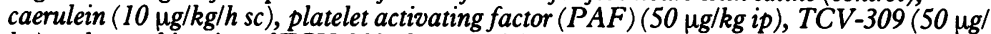
$\mathrm{kg}$ ) or the combination of TCV-309 plus caerulein or platelet activating factor. Mean (SEM) of eight rats. Asterisk indicates significant increase above the control value. Cross indicates significant decrease below the value obtained with caerulein or platelet activating factor.

$\mu \mathrm{g} / \mathrm{kg}$ ip) caused significant reduction in basal protein secretion by about $30 \%$ and this was completely reversed when TCV-309 $(50 \mu \mathrm{g} / \mathrm{kg})$ was administered before the platelet activating factor injection (Fig 1).

Dispersed pancreatic acini obtained from rats infused for five hours with sc caerulein or given ip platelet activating factor showed usual dose response to caerulein added to the incubation medium in gradually increased concentrations (Table I). The maximal amylase response to caerulein of acini from saline (control) treated rats was achieved at $10^{-11} \mathrm{M}$ of caerulein, while that obtained from animals infused for five hours with caerulein, it occurred at $10^{-10} \mathrm{M}$ of caerulein. Similar shift to the right of the amylase response curve to caerulein was observed when the dispersed pancreatic acini were obtained from rats infused with caerulein plus TCV-309 or injected with platelet activating factor. The volume of pancreatic acini isolated from the saline treated rats was about $2 \cdot 2(0 \cdot 3) \mathrm{ml}$ per

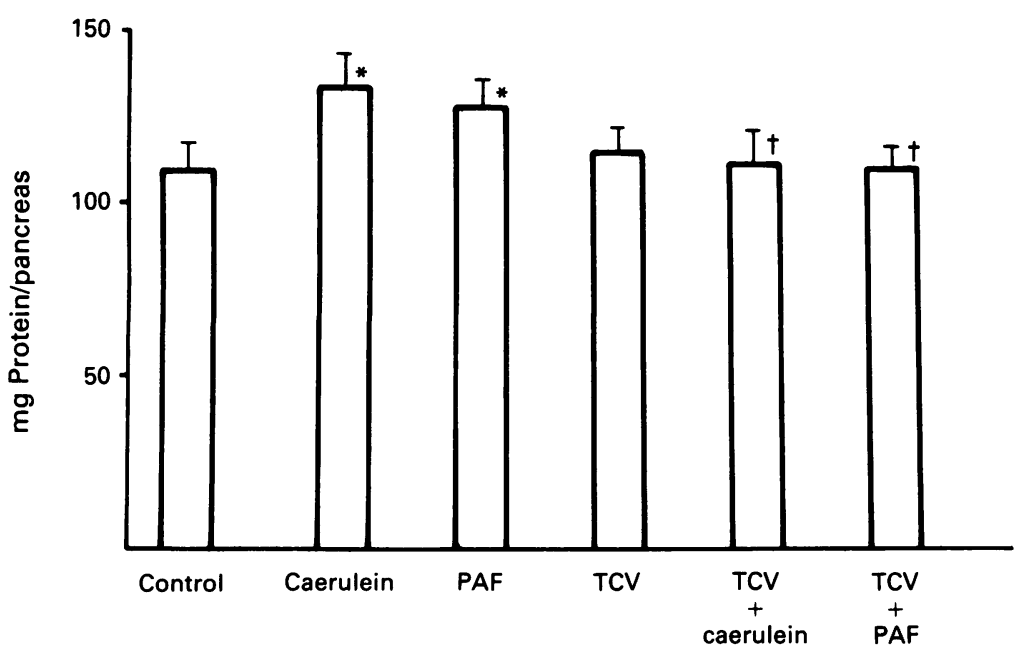

Figure 3: Protein content in the pancreas in tests as in Figure 2. pancreas, whereas that from the rats infused with caerulein and injected with platelet activating factor it was significantly $(\mathrm{p}<0.05)$ lower and declined to about $0.8(0.1) \mathrm{ml}$ and $0.9(0.2) \mathrm{ml}$, respectively. The volume of the acini obtained from rats infused with caerulein plus TCV-309 was also significantly reduced but that from platelet activating factor plus TCV-309 was not different from saline controls (Table I).

\section{MORPHOLOGICAL, CIRCULATORY, AND}

BIOCHEMICAL ALTERATIONS IN PANCREATITIS

Subcutaneous infusion of caerulein at a dose of $10 \mu \mathrm{g} / \mathrm{kg} / \mathrm{h}$ for five hours consistently produced pancreatitis in all tested rats. The pancreas appeared grossly swollen and enlarged with visible collections of oedematous fluid. Peritoneal fluid was present in all animals. Platelet activating factor injected ip $(50 \mu \mathrm{g} / \mathrm{kg})$ also resulted in the gross enlargement of the pancreas but the oedema and the pancreatic fluid collection were not seen. Caerulein infusion and platelet activating factor injection increased the weight of the pancreas by about $70 \%$ and $50 \%$ (Fig 2 ) and the protein content by $22 \%$ and $18 \%$, respectively (Fig 3). Plasma amylase concentrations rose by about $165 \%$ in rats infused with caerulein and $110 \%$ after injection of platelet activating factor (Fig 4). Histological changes such as oedema, cell infiltration, and vacualisation of acinar cells closely correlated the biochemic findings (Table II). In rats infused with caerulein, the interlobular oedema and moderate intralobular oedema were accompanied by perivascular infiltration of leucocytes and the presence of vacuolisation in over $50 \%$ of acinar cells. In rats given platelet activating factor, both oedema and leucocyte infiltration were less pronounced and the vacuolisation was observed in less than $25 \%$ of acinar cells (Table II).

Pancreatic blood flow as measured by laser Doppler flowmetry at the end of a five hour infusion of caerulein or five hours after injection of platelet activating factor was reduced by about $50 \%$ (Fig 5). As shown in Figure 6, the pancreatic blood flow measured in saline perfused control animals anaesthetised with ether was relatively well sustained throughout the experiments. In rats receiving sc caerulein, the blood flow was significantly $(\mathrm{p}<0.05)$ reduced by about $43 \%$ after two hours of caerulein infusion and then showed only small further decrease during the remaining hours of the experiment.

Pretreatment with TCV-309 before caerulein infusion significantly reduced the increase in pancreatic weight (Fig 2), protein content (Fig 3) and plasma concentration of amylase (Fig 4)'but all these parameters were significantly $(p<0.05)$ raised above the controls obtained from rats infused with saline. The fall in the pancreatic blood flow caused by caerulein was completely reversed by the pretreatment with TCV-309 (Fig 5 ). The pancreas appeared somewhat swollen and enlarged but peritoneal fluid was minimal. Cellular infiltration was significantly reduced but the extent of vacuolisation was not significantly different from that observed in animals infused with caerulein alone without pretreatment with TCV-309 (Table II). 


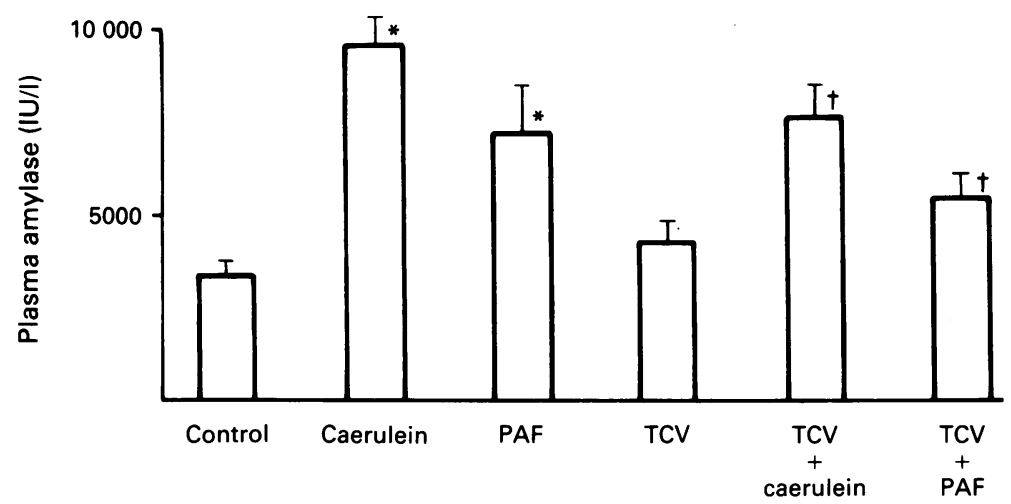

Figure 4: Plasma amylase concentrations in tests as on Figure 2.

Pretreatment with TCV-309 before the administration of platelet activating factor almost completely prevented the alterations in pancreatic weight, protein content, and blood flow caused by platelet activating factor (Figs 2-5). The pancreas appeared normal and histologically only small oedema and cellular infiltration or acinar cell vacuolisation were noticed (Table II). Plasma concentration of amylase was not different from the control value (Fig 4).

Pancreatic tissue obtained from intact rats infused with saline for five hours released only minute amounts of platelet activating factor (1.6 $(0.9) \mathrm{pg} / 100 \mathrm{mg}$ of wet tissue). Pancreatic specimens from rats infused sc with caerulein showed about nine-fold increase in the content of platelet activating factor $(13.9(5.5) \mathrm{pg} / 100 \mathrm{mg})$. In rats pretreated with TCV-309 plus caerulein, the content of pancreatic platelet activating factor was significantly $(\mathrm{p}<0.05)$ smaller $(4.5(1.6) \mathrm{pg} /$ $100 \mathrm{mg}$ ) than in those treated with caerulein alone but about three times higher than in saline treated rats.

\section{Discussion}

This study confirms that subcutaneous infusion of caerulein induced acute oedematous pancreatitis that was accompanied by a marked increase in the content of endogenous platelet activating factor in the pancreatic tissue and shows that the pretreatment with highly specific and potent platelet activating factor blocker

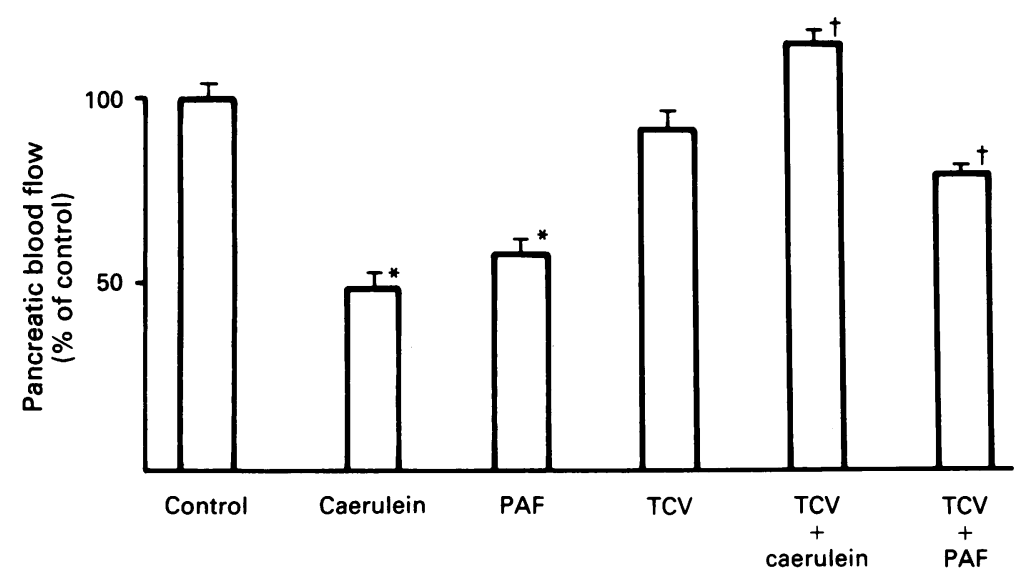

Figure 5: Pancreatic blood flow in experiments as in Figure 2.
(TCV-309) ameliorated the biochemical, circulatory, and histological manifestations of caerulein induced pancreatic damage. These results provide evidence that platelet activating factor plays an important role in the progression of pancreatitis induced by the overstimulation of the pancreas with caerulein.

Previous reports showed that caerulein administered intravenously at supramaximal dose is capable of inducing biochemical and morphological changes in the pancreas characteristic for acute pancreatitis. ${ }^{1-3}$ Robert et $a l^{3}$ used sc infusion of caerulein in rats and also observed the enlargement of the pancreas and histological alterations in the pancreatic tissue accompanied by a marked rise in plasma amylase concentration similar to these reported earlier after intravenous infusion. ${ }^{12}$ In their detailed study, the maximal increase in pancreatic weight was found after five to six hours of caerulein infusion and the optimal dose of sc infused caerulein to achieve oedematous pancreatitis was $5-10 \mu \mathrm{g} / \mathrm{kg} / \mathrm{h}$. In this study we also used the technique of continuous sc infusion of caerulein at a dose of $10 \mu \mathrm{g} / \mathrm{kg} / \mathrm{h}$ for five hours and this resulted in the increase in the pancreatic weight and the morphological alterations of pancreatitis comparable with that reported by Robert et al. ${ }^{3}$

Our study describes for the first time the secretory and circulatory changes occurring with the progression of pancreatitis induced by caerulein infusion. Pancreatic protein secretion in chronic pancreatic fistula rats infused with caerulein at supramaximal dose, that was used to induce the pancreatitis, showed a sudden rise, almost immediately after the start of infusion, reaching peak that was followed in the next hours by a marked decline to the level only slight above the baseline. As the severity of histological changes in the pancreas in response to caerulein such as the vacuolisation of acinar cells and the rise in plasma amylase concentrations were already significant at the third hour of infusion, it is obvious that the decline in the exocrine secretory activity might be attributed to the damage of acinar cells. The vacuoles appearing in these cells during infusion of caerulein contain activated lysosomal enzymes which in turn may activate the digestive enzymes leading to cell destruction and presumably to leakage of these enzymes into the interstitial tissue (where they produce inflammation) and into the blood."

It is of interest that the acini isolated from the pancreas damaged by caerulein responded to caerulein in the incubation medium with the concentration dependant increase in amylase secretion but this response curve was shifted to the right as compared with the acini obtained from saline infused rats. This indicates that acinar cells in pancreatitis retain their responsiveness to direct secretory stimulation but for some reasons they become 'resistant' to the stimulation in vivo. The reason for this apparent discrepancy is not obvious but the reduced secretory response in pancreatitis could be attributed to the marked fall in the pancreatic blood flow and to the reduction in the number of viable acinar cells in the pancreas. According to our experience the pancreatic blood flow in caerulein induced pancreatitis is significantly 
TABLE II Histological changes such as oedema, leucocyte infiltration and acinar cell vacuolisation, induced by sc infusion of caerulein alone $(10 \mu \mathrm{g} / \mathrm{kg} / \mathrm{h})$, ip administration of platelet activating factor alone $(50 \mu \mathrm{g} / \mathrm{kg})$, ip administration of TCV-309 $(50 \mu \mathrm{g} / \mathrm{kg})$ followed by infusion of caerulein or platelet activating factor and by TCV-309 alone

\begin{tabular}{llll}
\hline & Histolology & & \\
\cline { 2 - 4 } & $\begin{array}{l}\text { Oedema } \\
(0-3)\end{array}$ & $\begin{array}{l}\text { Infiltration } \\
(0-3)\end{array}$ & $\begin{array}{l}\text { Vacuolisation } \\
(0-3)\end{array}$ \\
\hline Caerulein alone & $2 \cdot 21(0 \cdot 11)$ & $1 \cdot 66(0 \cdot 13)$ & $2 \cdot 10(0 \cdot 18)$ \\
TCV-309+caerulein & $1 \cdot 82(0 \cdot 12)^{\star}$ & $1 \cdot 26(0 \cdot 16)^{\star}$ & $1 \cdot 85(0 \cdot 24)$ \\
Platelet activating factor alone & $1 \cdot 75(0 \cdot 22)$ & $1 \cdot 52(0 \cdot 20)$ & $0 \cdot 75(0 \cdot 14)$ \\
TCV-309+platelet activating factor & $0 \cdot 51(0 \cdot 10)^{\star}$ & $0^{\star}$ & 0 \\
TCV-309 alone & 0 & 0 & 0
\end{tabular}

Mean (SEM) of six to eight rats. ${ }^{\star}$ Indicates significant decrease below the value obtained with caerulein or PAF. reduced already after two hours of caerulein infusion and then this reduction progresses to reach after five hours of infusion about half of the normal flow. This could result in the tissue ischaemia leading to the decrease in secretory activity of acinar cells. The number of viable acini isolated in pancreatitis induced by caerulein was only about $30 \%$ of that obtained from the intact pancreas. Thus, the reported previously and observed in our study gradual 'resistance' of acinar cells to stimulation after the onset of acute pancreatitis in various animal models ${ }^{18}$ could be explained by the dramatic decline in the blood perfusion and ischaemia of the pancreatic tissue as well as the mortality of the large population of acinar cells.

This study shows that an excessive stimulation of exocrine pancreas by caerulein leads to an increase in the content of platelet activating factor in the pancreatic tissue and that the pretreatment with platelet activating factor blocker reduces this excessive secretory stimulation by caerulein and significantly ameliorates the biochemical, circulatory, and morphological changes in caerulein induced pancreatitis. These results indicate that platelet activating factor

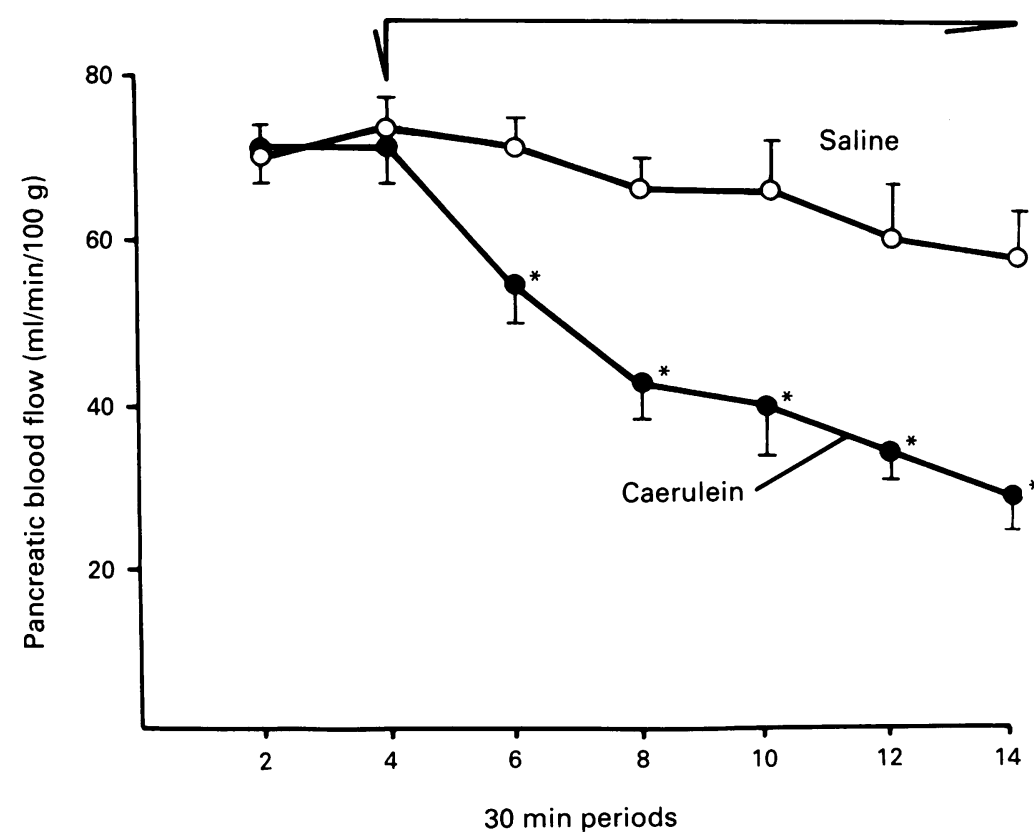

Figure 6: Pancreatic blood flow in rats infused sc with saline (control) or caerulein $(10 \mu \mathrm{g} / \mathrm{kg} / \mathrm{h})$ for five hours. Mean (SEM) of 10 rats. Asterisk indicates significant decrease below the control value in saline infused rats. may be an important factor in the progression of acute pancreatitis provoked by caerulein.

The origin of platelet activating factor released by the pancreas stimulated with caerulein is not known but it was shown earlier ${ }^{+}$that caerulein and cholecystokinin are capable of increasing the incorporation of labelled acetate into platelet activating factor in the isolated pancreatic lobules and to increase the synthesis of this phospholipid. The amounts of platelet activating factor like material detected in the pancreatic acini obtained from rats infused with saline in our study was lower than those reported previously for the isolated guinea pig acini from parotic glands ${ }^{+}$and comparable with those found in the gastrointestinal mucosa. ${ }^{1+19}$ According to our finding caerulein infused at supramaximal dose increased the production of platelet activating factor in the pancreatic tissue by about nine-fold. Such excessive contents of platelet activating factor could result in further stimulation of acinar cells as platelet activating factor is capable of inducing the secretion of enzymes, ${ }^{20}$ of reducing the blood flow, ${ }^{7}$ and increasing vascular permeability ${ }^{21}$ leading to tissue oedema and injury..$^{562}$ As the pretreatment with TCV-309 reduced the content of platelet activating factor in the pancreas of rats infused with caerulein, it is not excluded that the increase of platelet activating factor in the pancreas is, in part, secondary to the tissue damage by overstimulation with caerulein.

Some of the effects of caerulein infusion have been reproduced in this study by exogenous platelet activating factor and the results indicate that platelet activating factor administered in a single dose by itself can induce pancreatitis with typical enlargement of the pancreas and inflammatory changes in the tissue as well as in the increase in plasma amylase concentration. Platelet activating factor also caused a marked decrease in the pancreatic blood flow comparable with that observed after caerulein infusion. These changes induced by platelet activating factor can be almost completely reversed by the pretreatment with highly specific and potent platelet activating factor receptor blocker, TCV 309. Similar pancreatic injury was reported after the administration of platelet activating factor directly to the superior pancreaticoduodenal artery of rabbit."2 The pretreatment with a platelet activating factor blocker in this study also prevented the development of morphologic changes in the pancreatic tissue and the increment in plasma amylase concentration. These results support the concept that platelet activating factor is capable of inducing pancreatitis similar to that observed after infusion of caerulein and that it is mediated by specific platelet activating factor receptors.

There are, however, some differences in the action of caerulein and platelet activating factor on the pancreas. Although platelet activating factor is capable of stimulating enzyme secretion from the isolated acinar cells, ${ }^{20}$ according to our results, it actually inhibits this secretion in vivo and this inhibition can be reversed by the pretreatment with TCV-309. It is likely that the inhibition is mediated, at least in part, by the reduction in the pancreatic blood flow which is a 
well known limiting factor in exocrine pancreatic secretion..$^{23}$ Furthermore, pretreatment with a platelet activating factor blocker, which completely prevented the development of biochemical and morphological manifestation of platelet activating factor induced pancreatitis, only partly reduced the alterations involved in pancreatitis provoked by caerulein. This suggests that caerulein induces more severe pancreatitis than platelet activating factor and that, in addition to platelet activating factors, other mediators are probably involved in the pathogenesis of this pancreatitis. As the administration of platelet activating factor was reported to increase the release of leukotriene $\mathrm{C}_{4}{ }^{24}$ that is known to cause a potent vasoconstriction, ${ }^{23}$ it is likely that both platelet activating factor and $\mathrm{LTC}_{4}$ play a synergistic role in the pathogenesis of acute pancreatitis.

1 Lampel M, Kern HF. Acute interstitial pancreatitis in the rat induced by excessive doses of a pancreatic secretagogue. Virchows Arch [A] 1977; 373: 97-117.

2 Adler D, Hupp T, Kern HF. Course and spontaneous regression of acute pancreatitis in rats. Virchows Arch [A] 1979; 31: 282-94.

3 Robert A, Lum JT, Lancaster C, Olafsson AS, Kolbasa KP, Nezamis JE. Prevention by prostaglandins of caerulein induced pancreatitis in rats. Lab Invest 1989; 60: 677-91.

+ Soling H-D, Fest W. Synthesis of 1-0-alkyl-2-acetyl-snglycero-phosphocholine (platelet activating factor) in exocrine glands and its control by secretagogues. $f \mathrm{Biol}$ Chem 1986; 30: 13916-22.

5 Benveniste J. Paf-acether, an ether phospholipid with biological activity. In: Karnowsky ML, Leaf A, Bolis LC, eds Biological membranes; aberrations in membrane structure and Biological membranes; aberrations in membr.
functions. New York: Liss, 1988: 73-85.

6 Hahahan DJ. Platelet activating factor: a biologically active phosphoglyceride. Ann Rev Biochem 1986; 35: 493-509.

7 Wallace JL, Steel G, Whittle BJR, Lagente V, Vargaftig B Evidence for platelet-activating factor as a mediator of endotoxin-induced gastrointestinal damage in the rat. Gastroenterology 1987; 93: 765-73.

8 Emanuelli G, Montrucchio G, Gaia E, Dughera L, Corvetti G Gubetta L. Experimental acute pancreatitis induced by platelet-activating factor in rabbits. Am $\mathcal{F}$ Pathol 1989; 134 315-26.
9 Casals-Strenzel J, Heuer H. Pharmacology of PAF antagonists. Prog Biochem Pharmacol 1988; 22: 58-65.

10 Takatani M, Maezaki N, Imura Y, Terashita Z, Nishikawa K, Tsushima S. Platelet activating factor (PAF) antagonists: development of a highly potent PAF antagonists, TCV-309. A'dv Prostaglandin Thromboxane Leukotriene Res 1991; 21B 943-6.

11 Konturek SJ, Krzyzek E, Bilski J. The importance of gastric secretion in the feedback control of interdigestive and postprandial pancreatic secretion in rats. Regul Pept 1991; 36: 85-97.

12 Bernfeld P. Amylase alfa and beta. Methods Enzymol 1955; 5 $139-48$.

13 Lowry OH, Rosenbrough NJ, Farr AL, Randall RJ. Protein measurement with Folin phenol reagent. F Biol Chem 1951; 193: $265-75$.

14 Eliakim R, Karmeli F, Razin E, Rachmilewitz D Role of platelet-activating factor in ulcerative colitis. Gastroplatelet-activating factor in
enterology 1988; 95: 1167-72.

15 Dembinski A, Jaworek J, Konturek PK, Konturek SJ, Warzecha Z. Cholecystokinin receptor antagonism by Warzecha Z. Cholecystokinin receptor antagonism by peptidergic and non-peptidergic
$\mathcal{F}$ Physiol (Lond) $1989 ; 41: 419-35$.

16 Amsterdam D, Solomon TE, Jamieson JD. Sequential dissociation of exocrine pancreas into lobules, acini and individual cells. Methods Cell Biol 1978; 20: 362-78.

17 Watanabe O, Baccino FM, Steer ML, Maldolesi J. Supramaximal stimulation and ultrastructure of rat pancreatic acinar cell: early morphologic changes during developmen of experimental pancreatitis. Am $\mathcal{F}$ Physiol 1984; 246 G457-61

18 Niederau C, Niederau M, Luthen R, Strohmeyer G, Ferrel LD, Gredell JH. Pancreatic exocrine secretion in acute experimental pancreatitis. Gastroenterology 1990; 99 1120-7.

19 Kubes P, Ibbotson G, Russell J, Wallace JL, Granger DN Role of platelet activating factor in ischemia/perfusioninduced leukocyte adherence. Am 7 Physiol 1990; 259: G300-5.

20 Soling HD, Eibl H, Fest W. Acetylcholine-like effects of 1-0-alkyl-2-acetyl-sn-glycero-3 phoshocholine ('plateletactivating factor') and its analogues in exocrine secretory activating factor') and its analogues in
glands. Eur F Biochem 1984; 144: 65-72.

21 Hamphrey DM, McManus L, Hanahan DJ, Pinckard RN Morphologic basis of increased vascular permeability Morphologic basis of increased vascular permeability Lab Invest 1984; 50: 16-25.

22 Bonnet J, Loiseau AM, Orvoen M, Bessin P. Platelet activat ing factor acether (PAF-acether) involvement in acute inflammatory and pain processes. Agents Actions 1981;11: 559-61.

23 Konturek SJ, Pawlik W, Czarnobilski K, Gustaw P, Jaworek $J$, Beck G, et al. Effects of leukotriene $\mathrm{C}_{+}$on pancreatic secretion and circulation in dogs. Am F Physiol 1988; 254 G849-53.

24 Hseuth W, Gonzalez-Crussi, Arroyave JL. Sequential release of leukotriene and norepinephrine in rat bowel after platele activating factor. Gastroenterology 1988; 94: 1412-8. 